\title{
An Open Adaptive Virtual Museum of Informatics History in Siberia
}

\author{
Victor N. Kasyanov \\ Head of Laboratory of Program Construction and Optimization \\ A.P. Ershov Institute of Informatics Systems \\ Lavrentiev pr. 6, Novosibirsk, 630090, Russia \\ kvn@iis.nsk.su
}

\begin{abstract}
As with the history of any other science, the history of informatics (computer science), is an important and inseparable part of this science. In the paper, the Siberian Virtual Museum (SVM) project that is under development at the A.P. Ershov Institute of Informatics Systems and aimed at development of an open adaptive virtual museum of informatics history in Siberia is described. The conception of an open adaptive virtual museum and the objectives of the SVM project are discussed. The architecture and users of the SVM museum are considered. The adaptive virtual museum SVM is intended to be accessible annals of Siberian informatics history, which can be written by active users.
\end{abstract}

Keywords: Digital museum, virtual museum, open virtual museum, open adaptive virtual museum, informatics history in Siberia.

\section{Introduction}

With the advent of the digital age and the web, museums and cultural heritage institutions began rethinking their roles. An increasing number of museums make the decision to maintain a website (a digital museum) to provide useful information and attract new visitors. The advantage of digital museums is clear. The visitors of a digital museum can enjoy cultural relicts without a restriction of time and place, and complete safety of cultural relicts is guaranteed. The visitors have the opportunity to see precious cultural relicts that cannot be exhibited in a conventional way for reasons of safety or security. Furthermore, with the help of multimedia interaction, the visitors can even "touch" or "manipulate" the objects, which would be important for professionals. To extend access to networked browsing and querying, issues arise of collaboration between institutions and of standards for access [16].

Along with the "classic" digital museums which are websites of real museums, there are so-called virtual museums [7, 15, 17 - 21]. A virtual museum in this context refers to a repository of digital cultural and scientific resources that can be accessed and used anytime, anywhere via the internet. This means it is a website (a digital museum) that can but does not have to have any corresponding real museum and contains virtual exhibits being multimedia digital representations of any artifacts without a restriction of their nature or current state. For example, a virtual exhibit can present a painting being lost, a painter, a school of painting, or an art event. 
From the viewpoint of museum visitors, a real museum is an environment for excursions and expositions. On the other hand, museums are cultural heritage institutions intended to support collecting, research, making catalogues and exhibiting artifacts; however, museum visitors cannot take part in this important museum work. We believe that virtual digital museums can be "open museums" that allow extending this museum work to wide range of virtual museum users. We assume that it is useful that a museum user can propose a presentation of some real artifact as a virtual exhibit to an open virtual museum. In addition, an open virtual museum may also have facility to supply exhibits with author descriptions, to offer guided tours around the museum, and to make a curatorial exposition. These possibilities are very important for modern history museums. An open virtual museum [10] is a hypermedia system intended to be both an accessible repository for artifact collections and a cultural heritage institution supporting the collective work of many people, which are interested in collecting, annotating, organizing, research, making catalogues, and exhibiting these artifacts.

Adaptive hypermedia is an alternative to the traditional "one-size-fits-all" approach in the development of hypermedia systems [2]. Adaptive hypermedia systems build a model of the goals, preferences and knowledge of each individual user, and use this model throughout the interaction with the user to adapt to the needs of that user.

Open adaptive virtual museums can support the accessibility and active use of digital cultural and scientific resources for everyone without a restriction of time and place. They can bring several benefits described as follows.

- Collective work of many people who are interested in collecting, annotating, organizing, research, making catalogues and exhibiting any artifacts;

- Virtual exhibitions that cannot be organized otherwise, e.g. a comprehensive exhibition of an artist whose works are distributed all over the world in public and private collections;

- Private collections and artifacts can be made available for public, taking into account various levels of anonymity for the owner - anonymous, semianonymous (i.e. available for discussions under a nickname), non-anonymous, available for a visit, etc;

- Exhibitions on demand can be organized for visitors;

- Adaptive guided tours can take place for each individual visitor taking into account her interests, preferences and constraints (like time).

In the paper, the Siberian Virtual Museum (SVM) project of the open adaptive virtual museum of informatics history in Siberia is described [10 -12, 19]. The paper's structure is as follows. Section 2 presents the main objectives of the SVM project. The architecture of the SVM museum is briefly considered in Section 3. Section 4 describes the users of the SVM system. Section 5 provides a conclusion.

\section{Objectives of the SVM Project}

The history of informatics (or computer science), as with the history of any other science, is an important and inseparable part of computing. Teaching the history of computing has become a part of the computing curriculum of many Western 
universities. A special IFIP Joint Task Group has published a comprehensive report containing a number of valuable methodological instructions [8].

At the same time, informatics history of Eastern Europe and the USSR was practically unknown in Western Europe, although some works on this problem have been published [5, 6]. In 1996, the IEEE Computer Society, in connection with the 50th anniversary of its foundation, presented the Computer Pioneer Award to sixteen scientists from Central and Eastern Europe countries, including an outstanding Russian scientist and academician Alexej A. Lyapunov, who "developed the first theory of operator methods for abstract programming and founded Soviet cybernetics and programming" [4].

In Siberia, research in programming started after Alexej A. Lyapunov and his disciple Andrei P. Ershov had arrived to the Novosibirsk Academgorodok (in the early 1960s). Academician A.P. Ershov and his followers have founded the Siberian school of programming and informatics; this was the third one in the USSR, after Moscow and Kiev. Now, many years after its founder A.P. Ershov died [1], it continues to pay an important role in spite of all the difficulties endured by the Russian science and education. This gives us an opportunity to investigate independently the formation and development of informatics in Siberia, namely, in the Novosibirsk Scientific Centre, against the Russian and world scenes.

For fifty years, informatics had developed very intensively in Siberia, but by now some active participators and eyewitnesses of its development have died, many facts have been lost, and some are still unknown. So, it is very important to have an open virtual museum of informatics history in Siberia. It is believed that this museum can take the form of accessible annals of the Siberian computer science history, which can be written by active users.

Most of the museums presented on the www now are traditional hypermedia systems and provide the same information and navigation methods to all users. At the same time, a few papers discuss how the design of websites containing museum information could be improved to take into account various needs of different visitors. Paper [13] describes the use of natural language generation technology in the construction of personalized virtual electronic catalogues for a variety of domains such as digital museums, encyclopedia, and tourist guides. Paper [3] describes an evolution of the intelligent labeling explorer (ILEX), a system that dynamically generates personalized text labels for exhibits in a museum's jewelry gallery. Paper [14] describes a portable system (an adaptive museum guide implemented on a handheld computer), which provides a visitor with personalized navigation help and information about visited objects.

The SVM is intended for use by different categories of users, and it is very important that museum users with different preferences, goals, knowledge, and interests may obtain different information and may use different ways of navigation. Therefore, we give a particular attention to adaptation problems in our project [10 - 12].

\section{Architecture of SVM}

Currently, databases (DBs) of the web-based SVM museum provide storage and processing of the information about the following objects: publications, archive 
documents, projects, data about scientists in informatics, scientific teams, various events concerning informatics history, conferences, and computers. All the above objects are the exhibits of the virtual museum. Every exhibit has the following main attributes: a Unique Universal Identifier (UUID) of an object, a name, sometimes a date, a brief description (or an annotation), a full description (or a file), a name of a person who presented this exhibit, the date of its addition, the possibility and permission of its modification and participation in exhibitions.

\subsection{Tours and Exhibits}

A set of exhibits united according to the thematic, chronological, or typological criteria can be represented as an exhibition or a tour (or an excursion). Both an exhibition and a tour have the following attributes: UUID, a name, a name of a person who created it, brief description, and reference(s) to the file(s) representing it contents. Main differences between an exhibition and a tour are the following.

- A tour is composed of one section (a file), while an exhibition can consist of several sections (exhibitions or sub-exhibitions);

- A tour is a story about the museum (elapsing in the time) followed by demonstration of its exhibits in a definite order. A tour, for example, may be a clip or a presentation for MS PowerPoint and may not only be in an online mode but sometimes even exist offline. In contrast to a tour, an exhibition consists of exhibits that a visitor is looking at by himself and only online. Usually, several ways of navigation, including a free movement among exhibits, are available.

All exhibitions (and tours) are divided into permanent and temporary ones. A hall of exhibitions and a hall of tours are designed as accessible to all users of the museum.

\subsection{Halls and Some Nomenclature}

There are also restricted halls in the museum: the library, the archive, the chronicle, the halls devoted to scientists in informatics, scientific teams, projects, computers, conferences, the hall of new exhibits and the hall of preparation of exhibitions and excursions. These halls are accessible only to registered users of the museum (see below).

The library consists of books, articles and so on. In addition to the general exhibit attributes, each library exhibit has a list of authors and other attributes.

The archive consists of text, graphic, audio, and video materials.

The chronicle of events contains a description of the most remarkable events of informatics history in Siberia.

The hall of scientists in informatics presents information about the prominent scientists in informatics. In addition to the general information, it provides the following data about scientists: their education, scientific degrees, titles and posts, scientific interests, the text of the biography, photos, the main publications and projects. 
The hall of scientific teams presents information about groups, laboratories and institutes. Along with the general attributes, each team has its address, etc.

The hall of projects provides information about projects in informatics including the dates of its beginning and finishing.

The hall of computers shows computers, which were used and created in the Siberian Division of the Russian Academy of Sciences. In addition, each exhibit has the name of the designer, and the photo.

The hall of conferences contains the following information about each scientific event: where and when it was held, its status, and the general exhibit information.

New entries to the museum (adding by users) are placed in the hall of new exhibits.

Exhibitions and excursions created by users of the museum are being composed in the hall of preparation of exhibitions and excursions.

\section{Users of SVM}

All users of the SVM web-based museum are divided in two main categories: unregistered users (visitors) and registered ones (specialists) with different access level to information resources.

Visitors have access only to the part of museum information that is opened for public access (for example, in the form of excursions and exhibitions). In this case, all resources are accessible only for review and search. Visitors are divided in two subcategories depending on their knowledge level of subject domain: beginners and experts. Beginners have an opportunity to look only at tours, and experts can also look at exhibitions and electronic conferences of users.

Specialists have access to reviewing all information resources of our museum, including restricted halls closed for public access; they can also take part in electronic conferences and write in a visitors' book.

All specialists are divided in two main groups depending on their level of access to resources: a group of simple specialists working only in the hall of new exhibits and a group of museum employees.

Volunteers, tour guides, and exhibition curator/designers are selected from a group of simple specialists. Volunteers have permissions to add new exhibits of any type. Tour guides may create their own tours, and curators/designers the exhibitions. Objects made up or added by them are initially placed in the hall of new exhibits, and then managers of the corresponding resources (for example, chief tour guide or head of exhibitions) decide whether to include them in the museum's resource. Volunteers, tour guides, and exhibition designers have no permissions to modify the museum databases.

A group of museum employees can be presented as a hierarchical structure, with a director (or the senior manager) at its very top. He has full authority to administrate the museum DBs, including DB of museum users.

The second level of the hierarchy consists of the managers (or administrators) of the corresponding museum resources. They are appointed by a director such as the head of exhibitions, the chief tour guide, the chief librarian, the chief archivist, the chief chronologist, the chief biographer, the chief expert on scientific teams, the chief planner, the chief engineer, or the chief secretary. Resource managers (administrators) 
have full authority to administrate DBs of the corresponding resource types. They also control specialists working with DBs of corresponding types of resources.

The third level of the hierarchical structure includes museum employees appointed by the managers of the corresponding types of resources such as librarians, archivists, historians, biographers, experts on scientific teams, planners, engineers, and secretaries. They have limited rights to change DBs of the corresponding resource types.

\section{Conclusion}

We considered the conception of an open adaptive virtual museum that supports the accessibility and active use of digital cultural and scientific resources for everyone without a restriction of time and place. We also presented the SVM project of an open adaptive virtual museum of informatics history in Siberia.

The main purpose of creating SVM is to save historical and cultural heritage, the history of creation and development of computer science in Siberia. The SVM is also intended to provide a free common access to pages of the true history of computer science in Siberia, and therefore to increase cultural and educational level of people. It can be used as accessible annals of Siberian computer science history, which can be written by active users.

The solutions here considered can be used in the development of other virtual museums related to modern history or needed in collective work of people from different places. They can also be useful in the development of digital websites of real museums to support integration of knowledge and skills of museum workers from different museums. In particular, they were used in the DAVON project, proposal of which was under development to submit to the Sixth Framework Program, Call 5. The DAVON project aims to develop methods and tools that support open adaptive virtual museums of art and science history in Europe.

Acknowledgment. The author is thankful to all his colleagues, taking part in research connected with elaboration of the SVM. The SVM project is based on informatics history pages of the web-system SIMICS [10] and is supported in part by the Russian Foundation for the Humanities (Grant No. 02-05-12010).

\section{References}

[1] Bjorner, D., Kotov, V.: Images of Programming. Dedicated to the Memory of A.P. Ershov. North-Holland, Amsterdam (1991)

[2] Brusilovsky, P.: Adaptive hypermedia. User Modelling and User-Adapted Interaction 11(1), 87-110 (2001)

[3] Cox, R., O’Donnell, M., Oberlander, J.: Dynamic versus static hypermedia in museum education: an evaluation of ILEX, the intelligent labelling explorer. In: Proceedings of the 9th International Conference on Artificial Intelligence and Education, Le Mans, pp. 181-188 (1999)

[4] CS Recognizes Pioneers in Central and Eastern Europe. IEEE Computer (6), 79-84 (1998) 
[5] Ershov, A.P.: A history of computing in the USSR. Datamation 21(9), 80-88 (1975)

[6] Ershov, A.P., Shura-Bura, M.R.: The early development of programming in the USSR. In: A History of Computing in the Twentieth Century, pp. 137-196. Acad. Press, New York (1980)

[7] European Virtual Computer Museum. Development of Computer Science and Technologies in Ukraine, http: / /www. icfcst.kiev.ua/museum/

[8] Impagliazzo, J., Campbell-Kelly, M., Davies, G., Lee, J.A.N., Williams, M.R.: History in the Computing Curriculum. IEEE Annals of the History of Computing 21(1), 4-16 (1999)

[9] Kasyanov, V.N.: SIMICS: information system on informatics history. In: Proceedings of International Conference on Educational Uses of Information and Communication Technologies.16th IFIP World Computer Congress, PHEI, Beijing (2000)

[10] Kasyanov, V.: SVM - Siberian virtual museum of informatics history. In: Innovation and the Knowledge Economy: Issues, Applications, Case Studies, Part 2, pp. 1014-1021. IOS Press, Amsterdam (2005)

[11] Kasyanov, V.N., Nesgovorova, G.P., Volyanskaya, T.A.: Adaptive hypermedia and its application to development of virtual museum of Siberian informatics history. In: Proceedings of International Conference PSI 2003, Novosibirsk, pp. 10-12 (2003) (In Russian)

[12] Kasyanov, V.N., Nesgovorova, G.P., Volyanskaya, T.A.: Virtual museum of informatics history in Siberia. Problems of Programming (4), 82-91 (2003) (In Russian)

[13] Milosavljevic, M.: Electronic Commerce via Personalised Virtual Electronic Catalogues. In: Proc. of 2nd Annual CollECTeR Workshop on Electronic Commerce (CollECTeR 1998), Sydney (1998),

http: / /www. dynamicmultimedia.com.au/papers / collecter98/

[14] Not, E., Petrelli, D., Sarini, M., Stock, O., Strapparava, C., Zancanaro, M.: Hypernavigation in the physical space: adapting presentation to the user and to the situational context. New Review of Multimedia and Hypermedia 4, 33-45 (1998)

[15] On-line Museum of Computer History. Project of MGTU, http: / / museum.iu4.bmstu.ru/project.shtml

[16] The CIMI Profile Release 1.0H A Z39.50 Profile for Cultural Heritage Information, http://www.cimi.org/old_site/documents/HarmonizedProfile/Har monProfilel.htm

[17] The Russian Virtual Computer Museum. Project of Eduard Projdakov, http: / / www. computer-museum.ru/

[18] The Virtual Museum of Manchester Computing, http: / /www. computer50.org/kgill/

[19] Virtual Museum of Informatics History in Siberia, http: / pco.iis.nsk.su/svm/

[20] Virtual School Museum of Computer Science, http://schools.keldysh.ru/sch444/MUSEUM/

[21] Virtuelles Museums der Informatik, http: / /www. fbi.fh-darmstadt.de/ vmi/ 